\title{
The Effect of External Stimulus Produced by Vibration Stimulus Instrument on Body Sway
}

\author{
Hiroshi Hirai $^{1{ }^{* *}, \text { Shinichi Demura }}{ }^{2}$, Tamotsu Kitabayashi ${ }^{3}$, Yoshimasa Matsuura $^{1}$ \\ ${ }^{1}$ Faculty of Liberal Arts and Sciences, Osaka Prefecture University, Osaka, Japan \\ ${ }^{2}$ College of Human and Social Sciences, Kanazawa University, Kanazawa, Japan \\ ${ }^{3}$ Faculty of Science, Tokyo University of Science, Tokyo, Japan \\ *Corresponding author: thh27155@osakafu-u.ac.jp
}

\begin{abstract}
This study aimed to examine the effect of right-left or front-back vibration stimulus-during standing on body sway. Subjects were 10 healthy young male adults. They had no evidence or known history of a gait, posture or skeletal disorder. After a weak vibratory stimulus $(20 \mathrm{~Hz})$ for $1 \mathrm{~min}$, subjects stood under the strong stimulus $(70 \mathrm{~Hz})$ of front-back or right-left vibratory for $1 \mathrm{~min}$. The subjects were measured body sway for $1 \mathrm{~min}$ before and after the above vibratory stimulus. Four body-sway factors (unit time sway, front-back sway, left-right sway, and the high frequency band power) were used as evaluation parameters. A significant decrease was found only in a unit time sway factor after vibratory stimulus. A significant difference between front-back and right-left vibratory stimuli was found only in a left-right sway factor and the latter stimulus produced a large change. In conclusion, even in the vibratory stimulus with the same intensity, body sway decreases after front-back stimulus, but increases after right-left stimulus. In short, the effect of vibratory stimulus on posture control system may differ by the vibratory direction.
\end{abstract}

\section{Keywords: body sway, vibration stimulus, external stimulus}

Cite This Article: Hiroshi Hirai, Shinichi Demura, Tamotsu Kitabayashi, and Yoshimasa Matsuura, "The Effect of External Stimulus Produced by Vibration Stimulus Instrument on Body Sway." American Journal of Sports Science and Medicine, vol. 5, no. 2 (2017): 38-43. doi: 10.12691/ajssm-5-2-4.

\section{Introduction}

People maintain a collapsing posture normally by integrating vestibular, visuosensory and somatosensory information from the central nervous system $[1,2]$. Postural adjustment function works when maintaining static upright posture without changing a support base and controls weak body sway within the base range. The information detected from muscle spindle which reacts muscle extension is sent to the central nervous system through sensory nerve fibers of centrality. The information from the central nervous system transmits command signal to muscles through $\alpha$-motor neuron and $\gamma$-motor neuron. The former controls extrafusal muscle fibers which exist in ventral spinal cord roots and the latter controls intrafusal muscle fibers.

As the above-stated, the mechanism of static postural adjustment transmits the information from proprioceptor of muscle spindle or tendon organ of Golgi when disturbance occurred, into the central nervous system, and performs postural adjustment based on information. To examine this mechanism, the equilibrium reaction test using a disturbance stimulus has been conducted [3,4,5]. Mille \& Mouchnino [3] reported that back excursion of body sway occurs when imposing forced vibration on triceps muscle during standing. However, the vibratory stimulus is not necessarily to be given only from one direction. In front-back vibration that tiptoe and heel parts go up and down alternately, posture is relatively easy controlled by the feed-forward control based on the prediction of the load quantity adding to ankle joins.

In a case of right-left vibration that right and left feet go up and down alternately as compared with a front-back one, vibratory stimulus affects also a head part and occurs "the reverse pendulum sway" that the head sways largely because a support basal surface is small and range of motion of ankle joints is also small. In short, it is considered that effect on postural adjustment differs by a stimulus direction.

In addition, also postural adjustment strategy to the vibration may differ if effect of vibration stimulus on postural adjustment differs. When giving front-back or right-left vibratory stimulus to a plantar within the range without exceeding a support basal surface (disturbance stimulus), from the above reason, it is hypothesized that effect on postural adjustment is larger in right- left vibration than in front-back one.

This study aimed to examine the effect on body sway when giving right-left or front-back vibration stimulus during standing.

\section{Methods}

\subsection{Subjects}

Subjects were 10 healthy young male adults (age: 24.3 \pm 2.0 years, height: $171.6 \pm 5.3 \mathrm{~cm}$, weight: $71.0 \pm 7.0 \mathrm{~kg}$ ). 
They had no evidence or known history of a gait, posture, or skeletal disorder. The purpose and procedure of this study were explained to them. Informed consent was obtained from all subjects. The experimental protocol was approved by the Ethics Committee on Human Experimentation of Faculty of Human Science, Kanazawa University (No.2012-03).

\subsection{Experimental Instrument}

The perfect body (Meisei, Inc.: MS-20) was used for the disturbance stimulus by vibration. This instrument can set vibrational frequency within a range of $20 \mathrm{~Hz}-70 \mathrm{~Hz}$. Frequency of vertical vibration can be adjusted with a range of 155-710 for $1 \mathrm{~min}$ (see Figure 1). Front-back vibration (condition1) and right-left one (condition2) was selected as disturbance stimulus. Center of body gravity sway was measured by an Anima's stabilometer G5500. This can calculate the COP of vertical loads from values of three vertical load sensors, which are located in the corners of an isosceles triangle on a level surface. The data sampling frequency was $20 \mathrm{~Hz}$.

\subsection{Experimental Procedure}

Subjects were divided into two groups who started from front-back (condition1) or right-left (condition2) vibration stimulus. Center of foot pressure movement was measured after participants sat quietly on a chair for $30 \mathrm{~min}$ to stabilize breathing and heart rates. After that, the measurement procedure followed a method prescribed in the standardization of the stabilometry test [6]. The subjects maintained a static upright posture with closed feet (Romberg posture) for $1 \mathrm{~min}$. After performing one condition, subjects performed another condition several days later. The intensity of disturbance stimulus was selected $70 \mathrm{~Hz}$ in which keeping standing position for 1 min is possible under both conditions based on results of the exploratory experiment. This vibration stimulus can be given about 710 times for $1 \mathrm{~min}$. It was judged that the intensity over the $70 \mathrm{~Hz}$ is difficult to measure because of violent head sway. After being used to weak vibratory stimulus $(20 \mathrm{~Hz})$ for $1 \mathrm{~min}$, subjects received the strong vibratory stimulus $(70 \mathrm{~Hz})$ of front-back vibratory stimulus or right-left vibratory stimulus for $1 \mathrm{~min}$. During measurement, it was confirmed whether subjects have subjective symptoms such as a fall risk or vomiting by vibratory stimulus or not (see Figure 2).

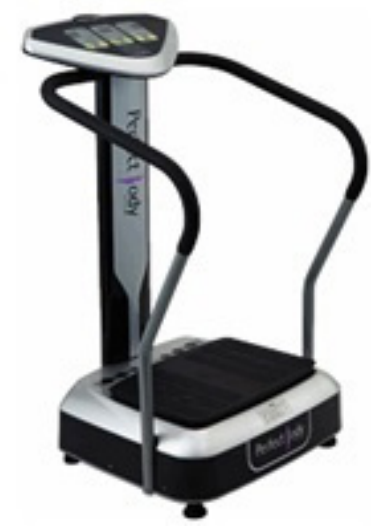

Figure 1. Experimental instrument in this study

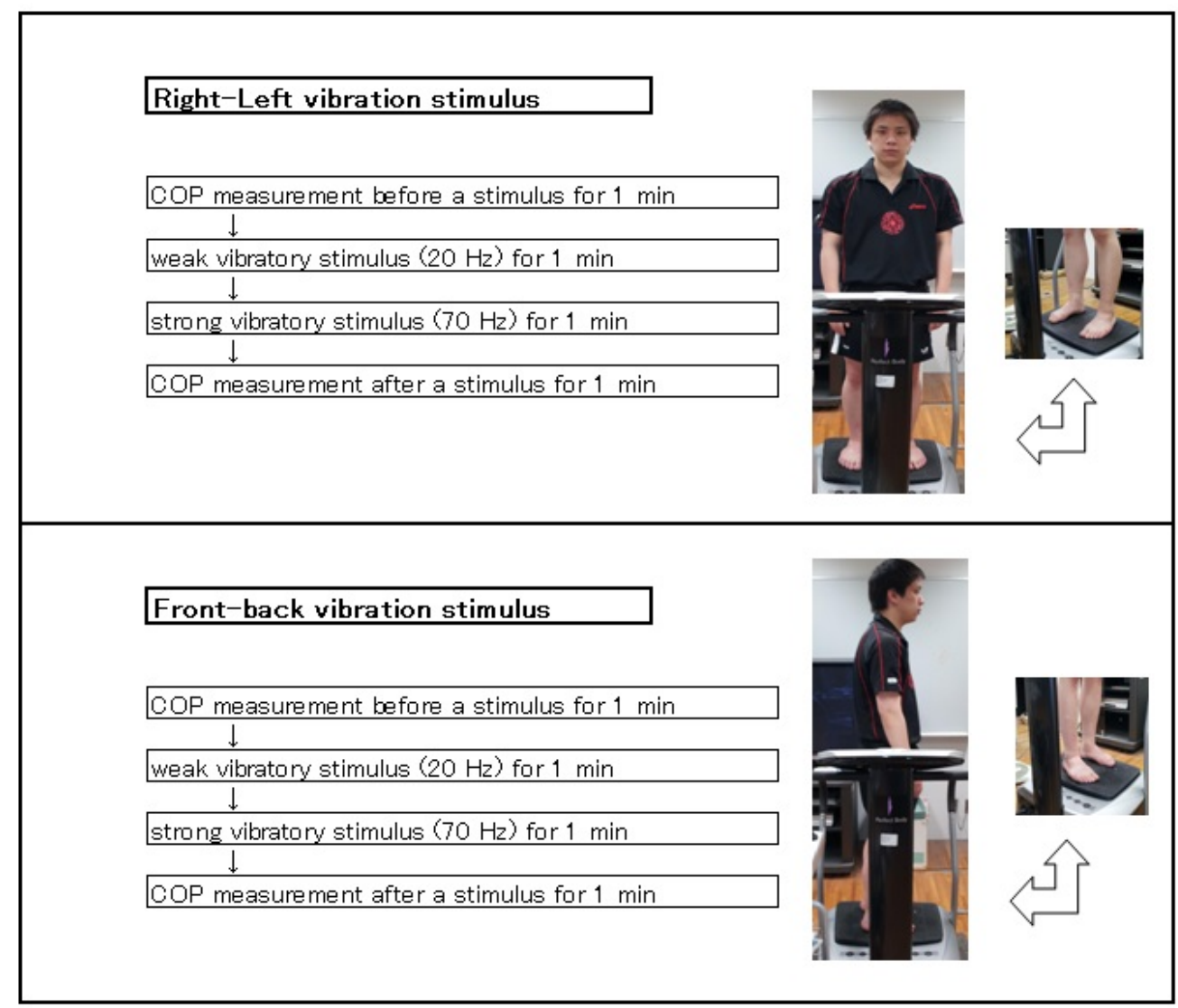

Figure 2. Experimental procedure in this study 
Table 1. Mean and Standard Deviation(SD) of Parameters

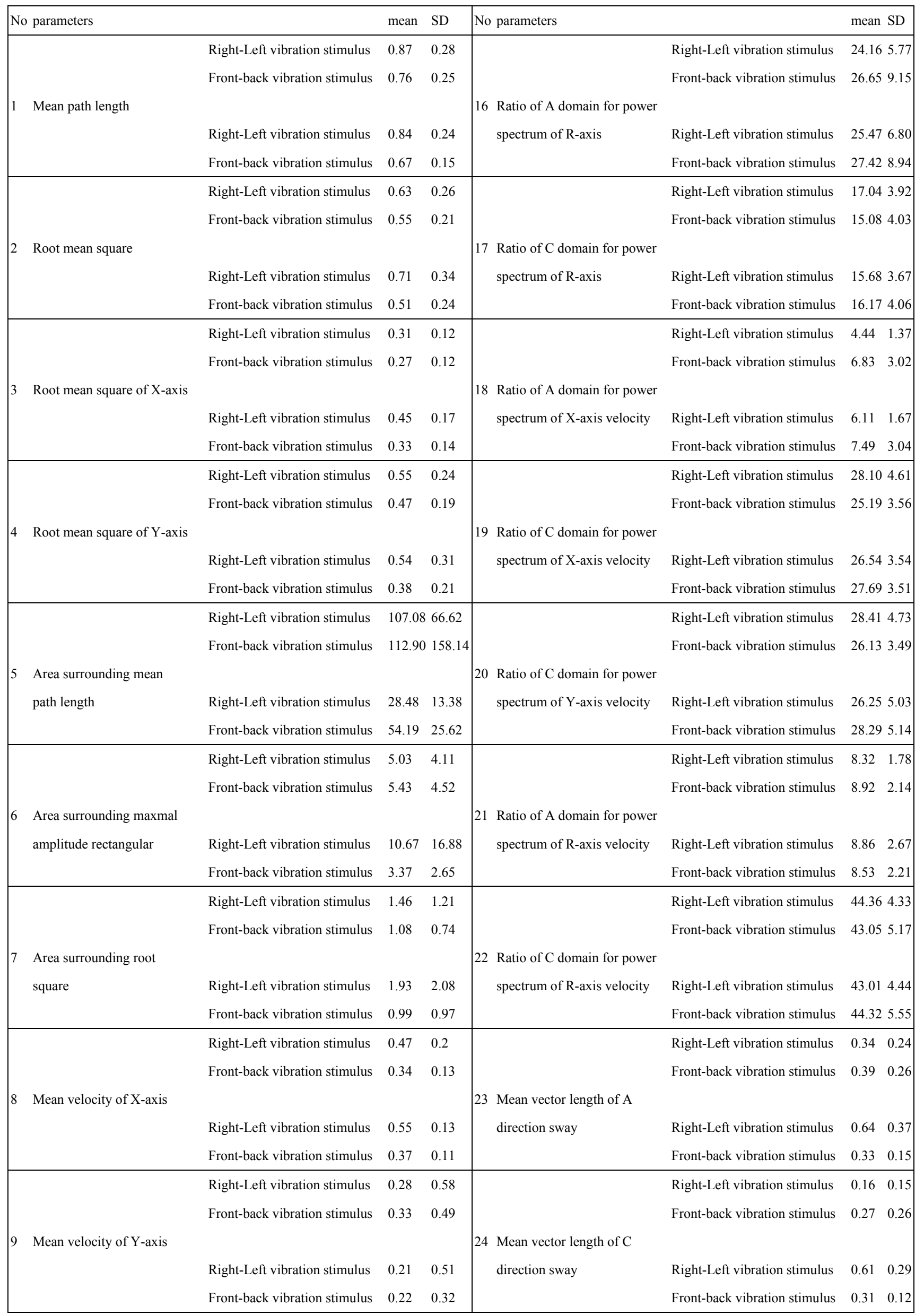




\begin{tabular}{|c|c|c|c|c|c|c|c|}
\hline No parameters & & mean & SD & No parameters & & mean & SD \\
\hline \multirow{5}{*}{$\begin{array}{l}10 \text { Root mean square of sway } \\
\text { velocity }\end{array}$} & Right-Left vibration stimulus & 1.19 & 0.36 & \multirow{5}{*}{$\begin{array}{l}25 \text { Mean vector length of } \mathrm{E} \\
\text { direction sway }\end{array}$} & Right-Left vibration stimulus & 0.45 & 0.32 \\
\hline & Front-back vibration stimulus & 1.07 & 0.38 & & Front-back vibration stimulus & 0.38 & 0.21 \\
\hline & & & & & & & \\
\hline & Right-Left vibration stimulus & 1.29 & 0.38 & & Right-Left vibration stimulus & 0.59 & 0.29 \\
\hline & Front-back vibration stimulus & 0.91 & 0.24 & & Front-back vibration stimulus & 0.40 & 0.32 \\
\hline \multirow{5}{*}{$\begin{array}{l}11 \text { Standard deviation of } \mathrm{X} \text {-axis } \\
\text { velocity }\end{array}$} & Right-Left vibration stimulus & 0.63 & 0.16 & \multirow{5}{*}{$\begin{array}{l}26 \text { Mean vector length of } \mathrm{G} \\
\text { direction sway }\end{array}$} & Right-Left vibration stimulus & 0.19 & 0.22 \\
\hline & Front-back vibration stimulus & 0.53 & 0.18 & & Front-back vibration stimulus & 0.20 & 0.17 \\
\hline & & & & & & & \\
\hline & Right-Left vibration stimulus & 0.94 & 0.25 & & Right-Left vibration stimulus & 0.52 & 0.20 \\
\hline & Front-back vibration stimulus & 0.65 & 0.25 & & Front-back vibration stimulus & 0.26 & 0.13 \\
\hline \multirow{5}{*}{$\begin{array}{l}12 \text { Standard deviation of } \mathrm{Y} \text {-axis } \\
\text { velocity }\end{array}$} & Right-Left vibration stimulus & 1.00 & 0.36 & \multirow{5}{*}{$\begin{array}{l}27 \text { Mean vector length of } \mathrm{A} \\
\text { direction velocity }\end{array}$} & Right-Left vibration stimulus & 0.52 & 0.19 \\
\hline & Front-back vibration stimulus & 0.93 & 0.36 & & Front-back vibration stimulus & 0.62 & 0.33 \\
\hline & & & & & & & \\
\hline & Right-Left vibration stimulus & 0.88 & 0.31 & & Right-Left vibration stimulus & 0.76 & 0.35 \\
\hline & Front-back vibration stimulus & 0.61 & 0.14 & & Front-back vibration stimulus & 0.46 & 0.10 \\
\hline \multirow{5}{*}{$\begin{array}{l}13 \text { Ratio of A domain for power } \\
\text { spectrum of X-axis }\end{array}$} & Right-Left vibration stimulus & 26.30 & 6.95 & \multirow{5}{*}{$\begin{array}{l}28 \text { Mean vector length of } \mathrm{C} \\
\text { direction velocity }\end{array}$} & Right-Left vibration stimulus & 0.31 & 0.24 \\
\hline & Front-back vibration stimulus & 34.87 & 9.20 & & Front-back vibration stimulus & 0.36 & 0.24 \\
\hline & & & & & & & \\
\hline & Right-Left vibration stimulus & 32.42 & 6.75 & & Right-Left vibration stimulus & 0.78 & 0.21 \\
\hline & Front-back vibration stimulus & 37.32 & 8.79 & & Front-back vibration stimulus & 0.54 & 0.24 \\
\hline \multirow{5}{*}{$\begin{array}{l}14 \text { Ratio of } \mathrm{C} \text { domain for power } \\
\text { spectrum of } \mathrm{X} \text {-axis }\end{array}$} & Right-Left vibration stimulus & 18.58 & 3.49 & \multirow{5}{*}{$\begin{array}{l}29 \text { Mean vector length of } \mathrm{E} \\
\text { direction velocity }\end{array}$} & Right-Left vibration stimulus & 0.50 & 0.22 \\
\hline & Front-back vibration stimulus & 13.17 & 3.96 & & Front-back vibration stimulus & 0.63 & 0.34 \\
\hline & & & & & & & \\
\hline & Right-Left vibration stimulus & 14.55 & 2.02 & & Right-Left vibration stimulus & 0.79 & 0.30 \\
\hline & Front-back vibration stimulus & 12.74 & 2.98 & & Front-back vibration stimulus & 0.46 & 0.08 \\
\hline \multirow{5}{*}{$\begin{array}{l}15 \text { Ratio of } \mathrm{C} \text { domain for power } \\
\text { spectrum of } \mathrm{Y} \text {-axis }\end{array}$} & Right-Left vibration stimulus & 16.12 & 5.07 & \multirow{5}{*}{$\begin{array}{l}30 \text { Mean vector length of } \mathrm{G} \\
\text { direction velocity }\end{array}$} & Right-Left vibration stimulus & 0.32 & 0.24 \\
\hline & Front-back vibration stimulus & 15.78 & 6.22 & & Front-back vibration stimulus & 0.37 & 0.24 \\
\hline & & & & & & & \\
\hline & Right-Left vibration stimulus & 14.83 & 4.71 & & Right-Left vibration stimulus & 0.84 & 0.26 \\
\hline & Front-back vibration stimulus & 15.41 & 4.56 & & Front-back vibration stimulus & 0.54 & 0.28 \\
\hline
\end{tabular}

F1: unit time sway factor $=($ No. $1,8,9,10,11,12,27,28,29,30)$

F2: front-back sway factor $=($ No. $2,4,5,6,7,16,23,25)$

F3: left-right sway factor $=($ No. $3,13,18,24,26)$

F4: high frequency band power spectrum factor $=($ No. 13, 15, 17, 19, 20, 21, 22)

\subsection{Evaluation Parameters}

This study used four body-sway factors (unit time sway, front-back sway, left-right sway and, the high frequency band power) proposed by Kitabayashi et al [7]. They reported that the above 4 factors are high reliability and adequately can evaluate body sway $[7,8]$. Table 1 shows mean and standard deviation (SD) of 30 parameters selected in this study.

\subsection{Data Analysis}

Two-way ANOVA (condition $\times$ before-after) was used to test differences among means of vibratory stimulus conditions (factor 1) and before-after stimulus (factor 2) for body sway parameters. When showing significant interaction or main effect, multiple comparisons were performed by Tukey's HSD method. Effect size (ES) was calculated to examine the size of mean differences. A t-test was used to examine mean difference of change-rate $(($ after value- before value) $\times 100 /$ (before value) $)$ before and after vibratory stimulus. An ES is generally interpreted as follows: under 0.2 is a small difference and over 0.8 is a large one. Factor scores of each factor were used the total of standard scores of parameters with high factor loadings followed the method of Kitabayashi et al [9]. The level of statistical significance $(\alpha)$ was set $\mathrm{p}<0.05$.

Table 2 shows results of two-way ANOVA and changerates of four body-sway factors. Significant interaction was found in unit time sway and left-right sway factors. A significant increase after vibratory stimulus was found only in unit time sway factor.

A significant difference between conditions (front-back and right-left vibratory stimuli) was found only in left-right sway factor, and right-left vibratory stimulus showed a larger value. In addition, the following tendency was found, but non-significant difference was found: unit time sway factor declines after front-back vibratory stimulus, left-right sway factor increases after left-right vibratory stimulus and declines after front-back vibratory stimulus. The high frequency band power factor declines after left-right vibratory stimulus and increases after front-back vibratory stimulus. 
Table 2. Results of two-way ANOVA and change-rates of four body-away factors

\begin{tabular}{|c|c|c|c|c|c|c|c|c|c|c|}
\hline \multirow[b]{2}{*}{ Evaluation par ameters } & & \multicolumn{2}{|c|}{ before } & \multicolumn{2}{|c|}{ after } & & & \multirow[b]{2}{*}{$\mathrm{p}$} & \multirow[b]{2}{*}{$\eta 2$} & \\
\hline & & mean & SD & mean & SD & & & & & \\
\hline \multirow{3}{*}{ unit time sway } & Right-Left vibration stimulus & 0.87 & 0.28 & 0.76 & 0.15 & $\mathrm{~F} 1$ & 0.87 & 0.37 & 0.09 & \\
\hline & Front-back vibration stimulus & 0.94 & 0.24 & 0.67 & 0.15 & $\mathrm{~F} 2$ & 9.18 & 0.01 & 0.50 & * \\
\hline & & & & & & IR & 10.8 & 0.01 & 0.55 & $*$ \\
\hline \multirow{3}{*}{ front-back sway } & Right-Left vibration stimulus & 3.98 & 6.55 & 4.00 & 12.3 & $\mathrm{~F} 1$ & 2.11 & 0.18 & 0.19 & \\
\hline & Front-back vibration stimulus & 0.22 & 8.91 & -2.3 & 4.27 & $\mathrm{~F} 2$ & 0.29 & 0.60 & 0.03 & \\
\hline & & & & & & IR & 0.33 & 0.58 & 0.04 & \\
\hline \multirow{3}{*}{ left-right sway } & Right-Left vibration stimulus & -4.7 & 2.67 & -1.4 & 4.7 & F1 & 20.1 & 0.00 & 0.69 & $*$ \\
\hline & Front-back vibration stimulus & 1.84 & 4.81 & 0.15 & 4.52 & $\mathrm{~F} 2$ & 1.72 & 0.22 & 0.16 & \\
\hline & & & & & & IR & 5.17 & 0.05 & 0.36 & $*$ \\
\hline \multirow{3}{*}{ the high frequency band power } & Right-Left vibration stimulus & 1.42 & 4.56 & -1.7 & 4.12 & $\mathrm{~F} 1$ & 0.94 & 0.36 & 0.09 & \\
\hline & Front-back vibration stimulus & -1.1 & 2.98 & -0.5 & 4.06 & $\mathrm{~F} 2$ & 1.23 & 0.30 & 0.12 & \\
\hline & & & & & & IR & 4.11 & 0.07 & 0.31 & \\
\hline
\end{tabular}

F1: main effect (condition), F2: main effect (befor \& after), IR: interaction, *: $\mathrm{p}<0.05$

p: probability, $\eta 2$ : effect size.

Table 3. Results between means of change rate for four body-sway factors

\begin{tabular}{|c|c|c|c|c|c|c|c|c|}
\hline Evaluation parameters & mean & SD & mean & SD & $\mathrm{t}$ & & $\mathrm{p}$ & ES \\
\hline unit time sway & 2.60 & 34.1 & -101 & 113 & 2.63 & $*$ & 0.01 & 1.18 \\
\hline front-back sway & 42.0 & 192.0 & 31.2 & 167 & 0.13 & & 0.90 & 0.06 \\
\hline left-right sway & 48.3 & 170.4 & -37.7 & 166 & 1.08 & & 0.29 & 0.48 \\
\hline the high frequency band power & 257.6 & 971.2 & 31.3 & 205 & 0.68 & & 0.5 & 0.31 \\
\hline
\end{tabular}

t: t-value, p: probability, ES: effect size, $*$ :p $<0.05$.

\section{Results}

Table 3 shows the test results between means of change rate for four body-sway factors. Significant difference was found only in unit time sway factor, and being larger in right-left vibratory stimulus $(\mathrm{ES}=1.18)$.

\section{Discussion}

Kitabayashi, et al. [7] reported that body sway of healthy young people can be explained by four sway factors (unit time sway, front-back sway, left-right sway and high frequency band power) and they are useful parameters to evaluate their body sway. Hence, this study examined effects of external stimulus (right-left or front-back vibration) produced by vibration stimulus instrument on body sway using the above-stated sway factors. A significant change was found in unit time sway factor after both vibration stimuli, but was not found in 3 factors of front-back sway, left-right sway and high frequency band power. This unit time sway factor evaluates mainly a size of body sway [7]. It is considered that body sway stabilized because this factor value declined after vibration stimulus. Fujiwara et al. [10] reported that reflection involves when giving disturbance stimulus. It is inferred that control by recovery reflection to make standing posture stable worked after both vibratory stimulus. In addition, a significant difference between conditions was found only in left-right sway factor, and front-back stimulus was a larger value than right-left one. This sway factor is related to the function of the labyrinthine recovery reflection which recovers standing posture to right position or maintains it [7]. In short, it is considered that recovery reflection works greatly after right-left vibratory stimulus and controls body sway. Although insignificant change was found, left-right sway factor increased markedly after the above stimulus. Also from the above, when giving right-left vibratory stimulus, it is inferred that body sway to an opposite direction increases and body sway to right and left direction is repeated greatly to recapture right standing posture. Mille and Mouchnino [11] reported that when vibrating the gastrocnemius compulsorily during standing, back displacement of center of body gravity occurs and after being released from vibration, the rapid forward displacement appears. In addition, Ouchi et al [12] reported that after stopping vibration, transient recovery arises and the following also occurs: the peak magnitude of front-back ingredient becomes large, body sway distance does not change regardless of a size of stimulus and the vibration stimulus of low frequency shows a large change. It is inferred that vibratory stimulus gave destabilizing effect to the proprioceptive sensation of the antigravity muscles during standing also in this study. Previous studies $[3,4,5]$ regarding the effect of vibratory stimulus on COP regulation clarified that the posture can be held within a range of $\pm 20 \%$ of targets after the stimulus. In addition, when adding stimulus which produces a posture change, change of body sway is well reproduced by the intermittent control model rather than the control model. By suitable stimulus, the feedback input regarding inclination of the posture obtained from feet is reinforced [13]. From now, it will be necessary to examine the vibratory stimulus amplitude, stimulus time, etc., according to age and whether vibratory stimulation is 
effective as balance re-learning or a sensory feedback function of postural adjustment.

\section{Conclusion}

In conclusion, even in the vibratory stimulus with the same intensity, body sway decreases after front-back vibratory stimulus, but increases after right-left vibratory one. In short, the effect on posture control system may differ by direction of the vibratory stimulus.

\section{References}

[1] Brooke-Wavell, K., Perrett, L. K., Howarth, P. A., \& Haslam, R. A. Influence of the visual environment on the postural stability in healthy older women. Gerontology, 48, 293-297, 2002.

[2] Pyykko, I. Evaluation of postural stability. Equilibrium Research, 59, 401-407, 2000.

[3] Mille ML, Mouchnino L. Are human anticipatory postura adjustments affected by a modification of the initial position of the center of gravity? Neurosci Lett 242: 61-64, 1998.

[4] Testerman, T \& Vander, R. Evaluation of ankle instability using the Biodex Stability System. Foot Ankle Int 20, 5, 317-321, 1999.
[5] Madurreria, M. Balance training program ishighly effective in improving functional statusand reducing the risk of falls in elderly womenwith osteoprosis: a randomized controlled trial. Osteoporos Int 18,419-425, 2007.

[6] Japan Society for Equilibrium Research. A fact of equilibrium research. Nanzando, Japan. 1994. [in Japanese].

[7] Kitabayashi, T., Demura, S., \& Noda, M. Examination of the factor structure of center of foot pressure movement and crossvalidity. Journal of Physiological Anthropology and Applied Human Science, 22, 265-272, 2003.

[8] Demura, S., Kitabayashi, T., Noda, M., Yamada, T., \& Imaoka, K Proposal for a convenient evaluation method of center of foot pressure. Equilibrium Research, 63, 215-223, 2004. [in Japanese].

[9] Kitabayashi, T., Demura, S. Proposal for a new body sway evaluation method. Perceptual and motor skills, 113, 1, 1-12, 2011.

[10] Fujiwara K, Ikegami H. The characteristics of postural response in upright stance to floor vibration. Jpn J Phys Educ 29: 251-261, 1984. [In Japanese with English Abstract].

[11] L. Mouchnino, M.-L. Mille, M. Cincera A., Bardot A., Delarque A., Pedotti J., Massion. Postural reorganization of weight-shifting in below-knee amputees during leg raising. Experimental Brain Research June 1998, Volume 121, Issue 2, 205-214, 1998.

[12] Ouchi, Y., Okada, H., Yoshikawa, E., Nobezawa,S., Futatsubashi, M. Brain activation duringmaintenance of standing postures in humans.Brain. 122 (Pt 2), 329-338, 1999.

[13] Brandt,T Krafczyk, S and Malsbenden, I. Postural imbalance with head extension: Improvement by training as a model for ataxia therapy. Annals of the New York Academy of Science 374, 636-49, 1981 